\title{
BUCHBESPRECHUNGEN
}

\author{
Murad Wilfried Hofmann \\ Der Islam als Alternative \\ Eugen Diederichs Verlag, München 1992, 214 S., DM 19,80
}

Dem Titel nach könnte es sich um eine religionswissenschaftliche Abhandlung oder - wenn man auf die Person des Verfassers abstellt - um die Bekehrungsgeschichte eines zum Islam konvertierten Deutschen handeln, was in beiden Fällen hier nicht zu behandeln wäre. Hofmann selbst aber definiert die Zielrichtung seines Buches ganz anders, nämlich als "Plädoyer für den Islam ... als Alternative zur postindustriellen westlichen Gesellschaft" (S. 7 f.). Dies aber geht jeden Juristen unmittelbar an, betrachtet doch der Islam als "integristische" Religion die im Westen axiomatisch gewordene Trennung von Staat und Religion als illusionär (S. 114) und durchdringt das gesamte staatliche und gesellschaftliche Leben. So behandeln neun der zwanzig Kapitel denn auch rechtliche Themen im engeren Sinne: Staats- und Völkerrecht, Straf- und Zivilrecht. Von diesen soll im folgenden in erster Linie die Rede sein, wobei auch zu prüfen sein wird, inwieweit der Verfasser seinem selbst aufgestellten Anspruch gerecht wird, sein Thema "wissenschaftlich fundiert, problembewußt und doch frei von Apologetik" (S. 7) zu behandeln.

Eingangs ist festzuhalten, daß Hofmann den klassischen sunnitischen Islam vertritt: Jegliche Mystik erscheint ihm als Hybris (S. 71), die schi'itische Glaubensrichtung bezeichnet er als exotisch (S. 108). Zur Erklärung des Phänomens "Islamische Republik Iran" findet der Leser also nichts. Da aber die überwiegende Mehrheit der Muslime Sunniten sind und auch die meisten europäischen Konvertiten dieser Richtung angehören, ist sie für uns ganz sicher am relevantesten.

Mit Recht betont der Verfasser, daß der Islam bis ins Zeitalter der Aufklärung toleranter war als das Christentum, jedenfalls gegenüber den im Koran erwähnten "Buchreligionen" der Juden und Christen, als deren Vollender er sich empfindet (S. 29 ff., 97 ff.). Auch ist die Blüte der islamischen Wissenschaft und Kunst im Mittelalter ein überzeugender Beweis dafür, daß der Islam als solcher nicht fortschrittshemmend oder kulturfeindlich sein muß (S. $53 \mathrm{ff}$., $137 \mathrm{ff}$.). Wenn der Verfasser aber unter Ausklammerung der von ihm beklagten gegenläufigen Entwicklung seit dem Spätmittelalter (S. 56 f.) diese Haltung auch für den heutigen Istzustand reklamiert (z.B. S. 100 f.), so ist dies doch eine sehr subjektive Darstellung. Die im Zusammenhang mit dem von Hofmann sehr skeptisch beurteilten christlich-islamischen Dialog aufgestellte Behauptung: "Daß Muslime zum Christentum nicht zu bekehren sind, ist allseits bekannt" (S. 50), ist in dieser Ausschließlichkeit schlicht falsch. Was nun den politisch-staatsrechtlichen Raum betrifft, so kommt Hofmann zu der erstaunlichen Feststellung, daß "der ideale islamische Staat eine rechtsstaatliche parlamentarische 
Republik ist" (S. 116), wobei er die Erklärung dafür schuldig bleibt, wieso bis heute kein islamischer Staat diese Kriterien erfüllt (S. 118). Der von ihm durchaus erkannten Gefahr "faschistoid-theokratischer" Entwicklungen setzt er nur ein "Gott möge dies verhüten" (S. 101) entgegen. Auf dem besonders brisanten Gebiet der Menschenrechte behauptet er bei höchst unterschiedlicher Herleitung - naturrechtliche Vorstellungen auf westlicher, göttliche Offenbarung auf der jedes Naturrecht wie auch Gewohnheitsrecht und Billigkeitsrecht ablehnenden islamischen Seite - eine nahezu vollständige Identität der Inhalte (S. 156 ff.), um dann doch fünf ganz fundamentale Abweichungen aufzuzählen: Nicht akzeptieren könne der Islam die völlige Gleichberechtigung von Mann und Frau, die Erlaubnis des Religionswechsels (d.h. "Abfall" vom Islam), den Zugang von Nichtmuslimen zum höchsten Staatsamt, die Abschaffung der Todesstrafe - dies wegen entsprechender koranischer Gebote - und die Ächtung der Sklaverei, da diese im Koran ausdrücklich toleriert werde (S. 159 ff.)! Nur im letzten Fall hält Hofmann, da der Koran ausdrücklich die Freilassung von Sklaven als besonders verdienstvoll preist, eine praktische Einigung für möglich (S. 161).

Zur rechtlichen Ungleichbehandlung der Frau liefert Hofmann eine Reihe Erklärungsversuche: Die für den Mann erheblich leichtere Ehescheidung wird darauf zurückgeführt, da $\beta$ er dabei auf die von ihm gezahlte Morgengabe verzichten müsse, während die Frau bei gleicher Behandlung sich in deren Besitz bringen könne (S. 170). Bei der nur dem Mann erlaubten Mehrehe wird einerseits behauptet, daß sie "weitestgehend verschwunden" sei ( $S$. 166), andererseits aber darauf verwiesen, da $B$ sich auch westlich erzogene Frauen in einer Mehrehe durchaus wohlfühlten (S. 168). Das dem Manne in Ausnahmefällen zugestandene Recht zur körperlichen Züchtigung seiner Frau wird als Notmaßnahme zur Rettung der Ehe (anstelle einer sonst zu befürchtenden Scheidung im Zom) gerechtfertigt (S. 170). Daß das Zeugnis einer Frau prozeßrechtlich nur halb so viel gelte wie das eines Mannes, wird daraus abgeleitet, daß "Frauen ... an bestimmten Tagen möglicherweise weniger zuverlässig wahrnehmen könnten" (S. 171)!

Hinsichtlich der Todesstrafe führt Hofmann aus, daß sie im Koran "nur" für Mord, Raub und Hochverrat gefordert, für Ehebruch und Verleumdung des Ehebruchs unter bestimmten Voraussetzungen zugelassen werde (S. $185 \mathrm{f}$.). Die im Westen immer wieder behauptete Todesstrafe für Abfall vom Glauben (Apostasie) gelte nicht für die private Glaubensentscheidung, sondern nur für die als Hochverrat gewertete aktive Wendung gegen den Islam (S. $98 \mathrm{f} ., 185,190$ ). Gerade diese Unterscheidung aber dürfte nach der das ganze Buch durchziehenden These von der Untrennbarkeit der privaten und öffentlichen Sphäre des Glaubens (besonders prägnant S. 114) im Islam gar nicht möglich sein. Zur Frage der von uns als unmenschlich empfundenen koranischen Körperstrafen (Auspeitschen, Amputation der Hand) weist Hofmann zu Recht darauf hin, daß sie wegen der hochgeschraubten Beweisanforderungen nur selten angewandt würden, was allerdings das Problem nicht aus der Welt schafft. Hierzu beruft er sich darauf, daß göttliche Gebote eben Gebote seien, "auch wenn sie menschliches Begreifen übersteigen mögen" (S. 189). Sein Hinweis, daß 
nach muslimischer Auffassung Haftstrafen nicht weniger inhuman seien, hilft hier nicht weiter.

Völkerrechtliche Probleme ergeben sich vor allem hinsichtlich des meist als "heiliger Krieg" übersetzten "dschihad", da der Islam ein eigenes Friedensvölkerrecht aufgrund der ihm innewohnenden universalistischen Tendenz mit Ausnahme des Grundsatzes der Vertragstreue nicht hervorgebracht hat. Dieser aber gilt für Muslime aufgrund göttlicher Offenbarung, nicht aber aufgrund der "naturrechtlichen Fiktion zwischenstaatlichen Rechts" (S. 200)! Zum "dschihad" betont Hofmann zu Recht, daß mit diesem Wort auch der innere Kampf um die eigene moralische Läuterung bezeichnet werde. Seine Behauptung aber, daß "dschihad" in seiner militärischen Bedeutung nur die Verteidigung, niemals aber einen Angriffskrieg rechtfertigen könne, vermag angesichts der von ihm selbst zitierten, allerdings nur auf einen bereits im Gange befindlichen Krieg bezogenen koranischen Weisungen ("tötet die Heiden, wo immer ihr sie findet", S. $192 \mathrm{ff}$.) nicht zu überzeugen.

Am Ende bleibt festzustellen, daß Hofmanns Buch seinem selbst gestellten wissenschaftlichen Anspruch zumindest dort nicht gerecht wird, wo der Verfasser unbestreitbare Fakten als "irrelevant" beiseiteschiebt (S. 194) oder zum Beweis seiner Behauptungen eigene frühere Veröffentlichungen zitiert (z.B. S. 153 Anm. 9; S. 196 Anm. 6). Trotzdem sollte es für jeden Pflichtlektüre sein, der sich für die unausweichliche geistige Auseinandersetzung mit dem Islam wappnen will. Daß einige Aussagen mit dem Grundgesetz kaum zu vereinbaren sind, dürfte deutlich geworden sein. Die sich aufdrängende Frage, wie jemand, der sie vertritt, die sich durch das Grundgesetz definierende Bundesrepublik Deutschland in islamischen Ländern zu vertreten vermag, ist hier nicht zu prüfen.

Karl Leuteritz

\section{Frank Zeidler}

Der Austritt und Ausschluß von Mitgliedern aus den Sonderorganisationen der Vereinten Nationen

(Europäische Hochschulschriften Reihe II, Band 905)

Peter Lang, Frankfurt/Bem/New York 1990, X, 335 S., DM 79,--

Die Heidelberger Dissertation untersucht umfassend einmal den Austritt und zum anderen den Ausschluß aus den 17 Sonderorganisationen der UNO.

$\mathrm{Da}$ der Austritt aus den Sonderorganisationen früher und heute ein aktuelles Problem ist, zeigt der Verfasser auf. Die von ihm analysierten 46 Austrittserklärungen liegen zwischen 1947 und 1987, erfassen primär Staaten des ehemaligen Ostblocks, aber auch Staaten wie die USA, Südafrika und Indonesien; sie erfassen selbst die eher apolitisch eingestuften Organisationen (wie die ICAO), wobei die WHO, die ILO/UNESCO und die FAO mit je 